\title{
Saúde dos povos de terreiro, práticas de cuidado e terapia ocupacional: um diálogo possível?
}

\author{
Maria Margarete Luiz de França, Sandra Bomfim de Queiroz, Waldez Cavalcante Bezerra
}

Universidade Estadual de Ciências da Saúde de Alagoas - UNCISAL, Maceió, AL, Brasil.

\begin{abstract}
Resumo: Este artigo é resultado de uma pesquisa realizada no terreiro de candomblé Casa de Iemanjá IyáOgun-Té, de nação Jejè/Nagô, e na Unidade de Saúde da Família Osvaldo Brandão Vilela, ambos em um bairro popular, hegemonicamente negro, do município de Maceió-AL. O objetivo foi contribuir com a fundamentação da atuação do terapeuta ocupacional na mediação dos diálogos necessários à implementação da Política Nacional de Saúde Integral da População Negra, com enfoque nos povos de terreiro. Trata-se de um estudo qualitativo, de abordagem etnometodológica, no qual a observação participante, o diário de campo e as entrevistas foram usadas como fonte de registros e produção dos dados. Como técnica de verificação dos dados foi utilizada a análise de conteúdo, a partir da qual emergiram duas categorias temáticas: a relação dos adeptos do candomblé com as questões e espaços de saúde e a percepção dos profissionais de saúde sobre os usuários e a Política de Saúde Integral da População Negra, com enfoque nos povos de terreiro. Os resultados evidenciaram a maior facilidade dos adeptos do candomblé em transitar nos diversos espaços de saúde, elegendo o terreiro enquanto espaço de acolhimento e resolutividade para os processos de equilíbrio em prol da saúde. Por parte dos profissionais de saúde, emergiu o desconhecimento do contexto sociocultural dos usuários e das políticas afirmativas do SUS para Povos de Terreiro. Concluiu-se que tais saberes pouco dialogam, necessitando de mediações para tal.
\end{abstract}

Palavras-chave: Politica de Saúde, Diversidade Cultural, Povo de Santo, Terapia Ocupacional.

\section{Health of worship place people, care practices and occupational therapy: a possible dialogue?}

\begin{abstract}
This article is the result of a research conducted at the candomblé field Casa De Iemanjá IváOgun-Té, of Jeié/Nagô nation as well as in the Unity of Family Health Osvaldo Brandão Vilela, both in the suburbs, mostly composed of black population, in the city of Maceió-AL. The goal was to contribute to the implementation of the occupational therapy procedure in mediating necessary dialogues to implement the National Policy of the Black Population Full Health Program, focusing on the people from the candomble fields. This is a qualitative study of ethnographically approach in which, the participating observation, the field diaries and interviews were used as sources of registration and data production. Content analysis was used as a technique to verify the collected data, from where 2 theme categories emerged: The relations of the practitioners of Candomble with health dedicated spaces issues and the perception from health professionals towards the National Policy of the Black Population Full Health Program, focusing on the people from the candomble fields. The results showed easiness of the practitioners of Candomblé in transiting through health dedicated spaces, using the Candomblé field as a place of refuge and resolution to balance processes towards health. As of the health professionals, we observed the ignorance and disregard towards the social and cultural situation of said users and the affirmative policies from SUS to the people from Candomblé fields. The study showed that these two areas of knowledge do not have enough dialogues, making it necessary to mediate the interactions between them.
\end{abstract}

Keywords: Health Policy, Cultural Diversity, People of Candomblé Fields, Occupational Therapy.

Autor para correspondência: Waldez C. Bezerra, Coordenação do Curso de Terapia Ocupacional, Universidade Estadual de Ciências da Saúde de Alagoas. R. Dr. Jorge de Lima, 113, Trapiche da Barra, 57010-300, Maceió, AL, Brasil, e-mail: waldezto@yahoo.com.br

Recebido em Dez. 01, 2014; $1^{\text {a }}$ Revisão em Jan. 19, 2015; Aceito em Maio 04, 2015. 


\section{Introdução}

Este artigo é resultado de uma pesquisa realizada no Núcleo de Cultura Afro-brasileiro Casa de Iemanjá Iyá Ogun-Té e na Unidade de Saúde da Família Osvaldo Brandáo Vilela, ambos situados em um bairro popular, hegemonicamente negro, do município de Maceió-AL. O objetivo foi contribuir com a fundamentaçáo da atuação do terapeuta ocupacional na mediação dos diálogos entre os distintos saberes que fundamentam as práticas de cuidado em saúde, mais especificamente aquelas executadas nos terreiros de candomblé, comunidades tradicionais ${ }^{1}$, e os dos moldes biomédicos, diálogos estes necessários à implementação da Política Nacional de Saúde Integral da População Negra. ${ }^{2}$

A motivação de pesquisar sobre os saberes populares de saúde dos povos de terreiro surgiu do reconhecimento da diversidade cultural com a qual o terapeuta ocupacional se defronta nos seus diversos espaços de trabalho e do interesse pessoal de melhor compreender os saberes desse povo em particular, como meio de reafirmar que temos que preservá-lo como força das nossas tradiçôes culturais ${ }^{3}$ e pensar o mundo de outra forma, valorizando a pluralidade da existência humana, com vista à alteridade e à ética, em uma relação dialógica com todos os seres vivos.

Ante a realidade de desumanização que o desenvolvimento capitalista impốe no imaginário da sociabilidade humana, nos inquietavam os olhares colonizadores do saber acadêmico sobre os saberes populares, como se estes últimos representassem o atraso, conhecimentos inválidos e que, portanto, não merecessem a nossa atenção, nem muito menos serem vistos como possibilidade de interaçóes e trocas.

Por conseguinte, nossa atenção se fará pelo conhecimento e reconhecimento do itinerário terapêutico dos povos de terreiros de candomblé, que têm em suas tradiçóes os fundamentos que orientam suas vidas e práticas. ${ }^{4}$

Para as religióes de matrizes africanas, o axé é a força propulsora de vida, estando presente nos seres humanos e em todos os elementos da natureza. $\mathrm{O}$ axé, como força vital, pode aumentar ou diminuir, causando o equilíbrio ou desequilíbrio de uma pessoa, de modo que as ervas, juntamente com os ritos, têm a funçáo de recompor e fortalecer a energia e promover saúde.

Reconhecendo a natureza distinta dos saberes que fundamentam as práticas de cuidado em saúde nos terreiros e nos espaços biomédicos, saberes estes muitas vezes conflitantes, percebe-se a possibilidade de a Terapia Ocupacional atuar na mediação e promoção do diálogo entre eles. Com isso, faz-se necessário refletir sobre alguns apontamentos teóricos que historicamente fundamentam o cuidado em saúde e que podem direcionar a práxis nos campos acadêmico e popular em saúde.

\section{Apontamentos sobre o cuidado em saúde nas práticas tradicionais de matriz afro-brasileira}

Segundo Czeresnia (1999), historicamente o conceito de saúde fundamentou-se e estruturou-se com base nas ciências positivas, em que saúde é ausência de doença e para a qual a medicina direcionou seu discurso acadêmico e/ou científico pautado na especialidade e na organizaçáo institucional das práticas em saúde, cujo objeto principal de intervenção é a doença e não o sujeito. Nessa visão, o conceito de doença estruturou-se no modelo biocartesiano e é percebida como dotada de realidade própria, externa e anterior às alterações concretas do corpo dos doentes.

O corpo é, assim, desconectado de todo o conjunto de relações que constituem os significados da vida. Cangilhem (1978) afirma que as práticas médicas acabam desconsiderando que entram em contato com uma pessoa e não apenas com seus órgãos e funçôes, sendo importante considerar que o discurso médico acadêmico tende a não contemplar a significação mais ampla da saúde e do adoecer.

Nesse raciocínio, do qual se pretende ampliar o conceito de saúde e ciência, Edgar Morin (2002), em O Problema Epistemológico da Complexidade, ressalta que não é possível tomar o conceito como capaz de substituir algo que é complexo, tendo em vista o ser na sua totalidade, sendo importante considerar outros saberes no campo da saúde, como as medicinas tradicionais e populares, que se baseiam em outros conceitos filosóficos, antropológicos e sociológicos de saúde para fundamentar a sua prática e agirem dentro de um sistema cosmológico.

De acordo com Camargo (1976), as medicinas populares são parte de um processo histórico, vivo e atual, ligado a três elementos étnicos que se amalgamaram para estruturação dos conhecimentos que hoje as constituem: o branco, o indígena e o negro. Elas são parte de um processo histórico e social que permanentemente se reatualiza no cotidiano da vida do campo e da cidade, no qual os ervateiros, raizeiros e parteiras colocam seus conhecimentos à 
disposição da comunidade e assim organizam suas experiências de vida e sua maneira de conceber o mundo. Através do trabalho, partilham seus saberes na comunidade e no enfrentamento das suas doenças e males, produzindo soluções numa relação de troca.

De acordo com Santos (1993), as culturas africanas, trazidas para o Brasil pelos negros escravizados pelos colonizadores portugueses, imprimiram suas marcas na arte de tratar e cuidar da saúde do povo. Alguns desses negros escravizados eram curandeiros que, por meio de práticas divinatórias, transes místicos e rituais específicos, invocavam as forças superiores para propiciar conselhos e intervençóes para problemas de saúde. Assim, o século XIX viu transportar, implantar e reformular no Brasil os elementos de um complexo cultural africano, que se expressa atualmente nos terreiros de candomblés.

Todo o saber em saúde dos povos de terreiro volta-se para uma estrutura mística trazida para o Brasil, que ainda existe e resiste nos centros urbanos e são responsáveis pela cura dos seus adeptos.

A liturgia dos Candomblés relacionada ao emprego dos vegetais é bastante diversificada e complexa, estreitamente ligada ao panteão das divindades afro-brasileiras cultuadas, às quais pertencem as ervas e nelas está depositado o axé (força vitalizadora das divindades). Desse modo, as plantas são empregadas em defumaçóes, beberagens ritualísticas, em preparados especiais com fins específicos como o amaci, ariaché, bori e em banhos. Destacamos os banhos de descarrego, empregados para eliminar fluidos pesados, onde há uma certa variedade de plantas que são utilizadas; as benzeduras para afastar o mau-olhado ou quebranto; os banhos de cheiro empregados para manter a felicidade e afastar as forças negativas e após o período de reclusão dos iniciados no candomblé (ARAÚJO, 1973, p. 193).

Os povos de terreiros, ao legitimarem as suas práticas, concebem duas categorias de doenças: as doenças do corpo e as da alma e/ou doenças materiais e espirituais. São os especialistas religiosos que fazem essa classificação. Para esses sacerdotes, Pais ou Máes de Santo, o adoecimento espiritual ou emocional atinge o corpo físico e, nesse caso, torna-se indispensável a procura de um médico. Para eles, o desequilíbrio espiritual e emocional promove o desequilíbrio orgânico, a chamada "doença de médico ou do homem da bata branca”, no linguajar dos terreiros. Existe também a identificação de problemas corporais por abusos e falta de cuidados, náo ligados diretamente às causas e espirituais e precisam apenas de intervenção dos profissionais da área da saúde. Enquanto os outros, de origem apenas espiritual, recebem a indicação de cuidados através de rituais religiosos com o uso de ervas e outros elementos litúrgicos, mesmo com sintomatologia física, geralmente casos de diagnósticos inconclusivos por parte de profissionais da saúde. Esse sistema de classificação vai permitir ao adepto da religião ou um cliente recorrer a um ou a outro sistema de cura, sem descredenciar o especialista não médico. É o Pai ou Mãe de Santo que recomenda a ida ao médico, de acordo com o diagnóstico realizado, com o auxílio do jogo de Ifá. ${ }^{5}$

Os processos identitários em curso nas Casas de Axé ou Terreiros levam seus adeptos a se tornarem mais conscientes de suas origens e da complexidade das relaçôes no mundo. Nesse contexto, há novos modos de articulação dos aspectos particulares e universais da identidade, na sua forma de ser e agir no mundo. Hall (1999) argumenta que a identidade cultural é parte constitutiva da identidade nacional, entendida no jogo entre saberes; portanto, se define como universal, se afirma a partir da história da sociedade e se constitui num modo de construir sentidos que vão ressignificar e organizar nossas açóes quanto ao entendimento que temos de nós mesmos e do mundo que nos cerca.

A saúde dos povos de terreiros é uma especificidade Política Nacional de Saúde Integral da População Negra. Assim, na perspectiva da referida política, considerar o reconhecimento, a desestigmatização e a valorização dos saberes e práticas terapêuticas de matriz afro-indígena-brasileira são fundamentais (OLIVEIRA, 2003), da mesma forma que o diálogo entre os conhecimentos tradicionais presentes nos terreiros e os conhecimentos técnicos propostos pelo SUS deve ser promovido.

A proposta de construção de uma política para a saúde da população negra possui uma história recente no Brasil, tendo como marco referencial a $3^{a}$ Conferência Mundial contra o Racismo, Discriminação Racial, Xenofobia e Formas Correlatas de Intolerância, realizada em Durban na África do Sul (ORGANIZAÇÃO..., 2001), e o I Seminário Nacional de Saúde da População Negra, realizado em Brasília no ano de 2004. Em 2006, foi aprovada a Política Nacional de Saúde Integral da Populaçáo Negra que traz em suas diretrizes a promoção do reconhecimento dos saberes e práticas em saúde preservados pelos terreiros (BRASIL, 2009). 


\section{0 campo de pesquisa e o percurso metodológico}

Trata-se de um estudo qualitativo, do tipo exploratório, com abordagem etnometodológica, através de uma imersão no campo de pesquisa. Os instrumentos de registro e produçáo de dados utilizados foram o diário de pesquisa, a observação participante e a entrevista semiestruturada. Como técnica de verificação dos dados, foi utilizada a análise de conteúdo, na modalidade temática, seguindo as proposições de Bardin (2011).

A pesquisa foi realizada no Núcleo de Cultura Afro-brasileiro Casa de Iemanjá IyáOgun-Té e na Unidade de Saúde da Família Osvaldo Brandão Vilela, entre os meses de março de 2013 a setembro de 2014. O Núcleo trata-se de um terreiro de candomblé de nação Jejè/Nagô, com 30 anos de história, fundado em 19 de fevereiro de 1984. É uma entidade filantrópica, sem fins lucrativos, de utilidade pública municipal e estadual, cujo

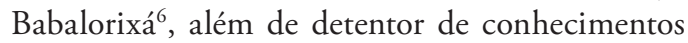
tradicionais, é o coordenador estadual da Rede Nacional de Religiosidade Afro-brasileira de Saúde.

O critério de inclusão utilizado, para os membros da Unidade de Saúde da Família (USF) foi o de que o sujeito fizesse parte do quadro de profissionais de nível médio ou superior da equipe de saúde da USF e, para os membros do terreiro, que o sujeito executasse práticas de cuidado no terreiro ou que já tivesse se beneficiado de alguma dessas práticas em algum momento da vida. Assim, em cada um dos locais, o projeto foi apresentado em reunião, junto àqueles que se enquadravam nos critérios de inclusão, e realizado o convite para participar do estudo. Assim, aceitaram fazer parte do estudo, assinando o termo de consentimento livre e esclarecido 7 , um grupo de 14 pessoas, sendo 5 profissionais da Unidade de Saúde da Família (USF) e 9 membros assíduos do Terreiro.

Foram utilizados os pressupostos teóricometodológicos qualitativos da etnometodologia, pois, de acordo com Minayo (2012), a pesquisa qualitativa é um tipo de pesquisa que busca compreender relaçôes, valores, atitudes, crenças, hábitos e representaçóes. Enquanto a etnometodologia dá nome ao conjunto de estratégias de pesquisa, cujo ponto comum é a descrição minuciosa dos objetos que investiga, por isso, é também conhecida como "pesquisa situada". De acordo com Minayo (2010, p. 149), "Os desenhos operacionais de cunho etnometodológico preconizam a observação direta e a investigação detalhada dos fatos, no lugar em que eles ocorrem, com a finalidade de produzir uma descrição minuciosa e densa das pessoas, de suas relações e de sua cultura”. Nesse sentido o pesquisador estabelece ou procura estabelecer a mediação entre seus próprios marcos de significados e os de outros atores sociais que compóem o campo de pesquisa.

Além da entrevista semiestruturada com os 14 sujeitos, também foi utilizada a observação participante como instrumento, na qual o pesquisador e o pesquisando estabelecem laços de maior proximidade. Permitindo, dessa forma, depoimentos mais espontâneos e íntimos em relaçáo às vivências no campo de pesquisa e às experiências de vida relacionadas com a temática objeto da pesquisa. A observação participante foi fundamental nos momentos em que foram vivenciados festas e rituais do Terreiro, no sentido de coleta de dados e disponibilização dos sujeitos de pesquisa. Utilizamos como estratégia de registro o diário da pesquisa que, segundo Barbosa (2010), promove um olhar apurado na realidade da pesquisa, incluindo nós mesmos no seu interior, sendo esse olhar de fora para dentro e de dentro para fora do contexto em que estáo envolvidos os pesquisadores e os sujeitos que participaram da pesquisa.

$\mathrm{Na}$ USF, o vínculo foi se constituindo de forma bastante singular, considerando a realidade das participantes da pesquisa e a forma de organização do trabalho na instituição, no qual o envolvimento com a temática foi significativo, mesmo contando com um tempo limitado para a realização das entrevistas devido às demandas do trabalho. As conversas se deram no horário de trabalho, após os atendimentos; às vezes, eram interrompidas pela chegada de usuário ou do gerente da unidade. Todas as conversas foram intensas e densas, garantidas pela construção de um bom vínculo, possível por relaçôes marcadas pela gentileza, solidariedade, atenção e colaboração. Isso foi uma marca muito importante no processo de pesquisa.

Com a inserção no campo de pesquisa, mais especificamente no terreiro, notamos que algumas pessoas nos olhavam com estranhamento, desconfiança, outros com ar de sorriso. Logo percebemos que no terreiro náo se chega e rapidamente se entra no espaço do outro. É preciso que haja a permissão, e ela é um processo, tudo tem a sua dinâmica. É preciso observar, sentir, esfriar o corpo, assentar-se e, na hora certa, aproximar-se; sem permissão não se pode circular pelo barracão.

O tempo de vivência e participação nas atividades do terreiro nos oportunizou mergulhar nesse rico universo cultural. Aos poucos, tudo foi se tornando familiar, podíamos chegar sem causar nenhum estranhamento, sentíamo-nos acolhidos por todos 
os membros da Casa. O Babalorixá representou o elo entre nós e os integrantes da pesquisa, o que inspirou confiança para que eles pudessem compartilhar seus saberes.

Sentimos, nas idas ao campo de pesquisa, o peso da responsabilidade de poder contar com a colaboração daquelas pessoas que livremente se dispuseram a participar deste estudo. Sentimos que a pesquisa já náo nos pertencia e tornava-se um bem coletivo, de um lugar especial e originalmente sagrado, no qual as pessoas buscam sentidos e constroem identidades, fortalecendo e afirmando suas ancestralidades.

Nesse processo, entendemos que não era a literatura previamente definida que daria corpo à teoria, mas o contrário, era o campo que proporcionaria a teoria. Esta experiência no campo nos fez entender que para se chegar a uma realidade que não nos é familiar, mesmo que já se tenha previamente alguma experiência, nunca é demais a humildade.

Para nós, o mais importante era a escuta sensível, deixar o sujeito falar, expressar suas concepçóes e suas identificaçôes com a temática. Desse modo, as entrevistas não seguiram um roteiro rígido, havendo liberdade para o entrevistado falar e trazer à tona o seu conhecimento e vivência com a temática em estudo. Todas as entrevistas foram gravadas em áudio, sendo em seguida transcritas na íntegra e as transcrições submetidas à análise de conteúdo.

\section{Resultados e Discussão}

Tomando como base os dados produzidos em campo e analisados através da técnica de Análise de Conteúdo, foram identificadas as seguintes categorias temáticas: 1) A relação dos adeptos do candomblé com questôes e espaços de saúde e 2) A percepção dos profissionais de saúde sobre os usuários e a Politica Nacional de Saúde Integral da População Negra, com enfoque nos povos de terreiro, considerando seus contextos, nos quais plasmam as suas vivências e práticas em saúde.

\section{- A relação dos adeptos do Candomblé com as questóes e espaços de saúde}

De acordo com Alves e Souza (1999), o itinerário terapêutico se traduz nos processos pelos quais os indivíduos, grupos sociais e comunidades escolhem, avaliam e aderem a determinadas formas de tratamento, no sentido de resolver os problemas de saúde. A escolha do tratamento tem relação com o contexto sociocultural e econômico que marca as trajetórias individuais e coletivas, no qual se viabiliza um campo de possibilidades socioculturais e históricas.
[...] o Pai de Santo que vai dizer o que é preciso ser feito para aquele caso. No terreiro se produz muitas coisas: produçóes de ervas, de chás, de banhos, tudo isso vai provocar seu bem-estar. Se o caso estiver relacionado às questôes espirituais ou quando não ainda, tipo casos médicos, que são resolvidos com chás, lambedor, produzido no terreiro, tipo: cicatrizante - tem na farmácia, mas dentro do terreiro também tem remédios produzidos com ervas de forma bem artesanal. Tem casos que são espirituais e exigem obrigaçōes e outras coisas; tem caso a ser resolvido aqui no terreiro, quando não, no jogo de búzio é dito para pessoa procurar um médico (Membro do Terreiro, 5).

O sentimento de família, de aconchego, foi muito forte e constante em várias falas. Bastide (1983) observou que o Candomblé é uma família mítica e que nele toda a vida, desde o nascimento até a morte, está marcada pela mística em que os ritos repetem os mitos e os mitos narram os acontecimentos dos tempos antigos.

O motivo de vir para cá foi o aconchego. [...] A gente faz Iâo, dar o bori, porque o bori é o fortalecimento da cabeça, é uma coisa de saúde, eu fico muito mais leve [...] Eu gosto de todo o processo do Iaô, porque o Iâ̂ vem sempre por algum motivo, problema de saúde e quando eu vejo que aquela pessoa está [...] melhorando pra mim é muito massa. [...] O criar é como uma gestação, fica no processo gestacional na Camarina, só entra pessoas especificas [...] A gente vai ensinar a rezar, os preceitos, tem coisa pra tudo, do dia e da noite e a gente vai ensinar. Muita gente chega aqui e diz: estou com uma dor de cabeça, ai vai tomar os banhos de ervas e a pessoa melhora (Membro do Terreiro, 6).

Nesse sentido, Motta (1988) ressalta que esses povos têm o conhecimento dos vegetais, com as suas propriedades terapêuticas e 'mágicas', que vão nortear o seu uso e propiciar a recuperação do indivíduo, processo este que se inscreve num contexto cosmológico, causado pela diminuiçâo ou distanciamento do Axé, no qual o vegetal pode atuar para o restabelecimento da unidade perdida, ou seja, da saúde.

Notamos que nos rituais iniciáticos e nos cultos são utilizados vegetais, no interior de um conjunto de crenças e saberes específicos, que vai caracterizar um universo cultural bem peculiar. Essas plantas empregadas para fins medicinais podem ser cultivadas no próprio terreiro ou compradas no mercado, como pudemos observar. 
Quando o assunto é do terreiro [...] A gente utiliza as ervas: faz banhos, chás; no terreiro não tem costume de se utilizar remédio de farmácia porque term uma erva chamada anador que serve para dor, tem uma erva chamada coesa, serve pra estômago, tem camomila, erva cidreira, que é calmante, tem hortelã de Santa Bárbara que serve pra dor de cólica, então são coisas que a gente tem no terreiro, que servem e náo precisa comprar em farmácia. Pra inflamação, a gente tem vários matos, aroeira, barbatimão (Membro do Terreiro, 8).

O uso das ervas em rituais de cura é constante, assim como a procura por saber se é caso espiritual ou de médico. Segundo Geertz, (1989), os rituais de cura se constituem, enquanto processo transformador, numa trama extraordinária de ritos e símbolos, carregados de significação e significado. Proporcionam aos seus participantes uma percepção nova neste universo e um novo posicionamento na trama da cura, entre material e imaterial, objetividade e subjetividade, em um jogo dinâmico de restabelecimento de saúde. É necessário entender a causalidade do problema e definir o foco da ação para a atividade de cura, na qual o "curador" e/ou a entidade direciona o tratamento, expulsando o mal, sendo o corpo fortalecido com o ritual. Efetiva-se uma série de procedimentos com a participação do sujeito envolvido, garantindo a restauração da integridade do corpo.

No candomblé o ensinamento é passado de pessoa para pessoa porque não há nada escrito. Aprendi vivendo o candomblé no dia a dia. Eu tive um problema na minha perna, procurei um médico ele disse que queria amputar porque o problema era muito grave; tomei várias injeçóes e não melhorou, então minha mãe procurou Pai de Santo e ele jogou os búzios e falou que o problema era espiritual, então foi feito o ebô. Fiquei seis meses sem poder caminhar. Após fazer as oferendas, outra entidade veio, colocou a boca no ferimento e puxou a secreção e com o passar dos dias foi secando, usaram muita aroeira, folha de pimenta samba caitá, folha de mamona (Membro do Terreiro, 8).

Como se pode observar, é o dia a dia que permite conhecer a dinâmica de um terreiro; os valores que ali circulam, as relaçóes estabelecidas entre os seus membros, a concepção de saúde compartilhada e vivenciada por eles e os modos de transmissão dos conhecimentos sobre as questóes de saúde. No candomblé, pouco se fala e muito se observa. Tudo nos mínimos detalhes e movimentos; exige-se muito desprendimento e abertura para aprender com as vivências, com as práticas; seja com o olhar ou com o gesto, o processo de interação vai se efetivando. Tudo tem um tempo. As pessoas são detentoras de saberes ancestrais que permanentemente se reatualizam, no aqui e agora. $\mathrm{O}$ ambiente é marcado por uma força que proporciona bem-estar e harmonia. Há no olhar e no movimento do corpo dos membros do terreiro um ar de soberania, altivez. A memória do passado se corporifica na vida de cada adepto. Tudo faz sentido no universo cultural deles, havendo todo um encantamento presente nos rituais que envolvem cantos, a força dos tambores que evocam os seus deuses, as vestes de cada Orixá, as oferendas que fortalecem o Axé e promovem saúde.

As práticas de saúde no terreiro: a cura, o banho, cura com ervas, jogo de búzio, os ebós, o bori; então, tudo isso são práticas do dia a dia do terreiro. [...] O que quer dizer Obori? Ebó no ori; ebó é obrigaçâo e ori cabeça; você vai alcançar junto com sua cabeça o seu equilibrio. Então toda a prática da religiosidade vai estar norteada pela saúde, que é o bem-estar e o equilíbrio do ser humano. E o equilibrio entre o homem e os deuses, entre o homem e Olorum - o Grande Senhor do mundo (Membro do Terreiro, 9).

Para os adeptos, sacerdotes e sacerdotisas do candomblé distinguir o que é ou não causado por desequilíbrio do Orixá ou do Ori, da energia pessoal da cabeça do filho de santo, parece ser de muita importância.

Fui para o médico, ele me receitou e eu tomei o remédio e fiquei bom. Se fosse do Orixá o meu problema não tinha passado, não tinha sido resolvido, então eu ia fazer as coisas do Orixá e lá ficava bom. [...] O terreiro de Candomblé tem relação direta com a energia do Orixá (Membro do Terreiro, 3).

Meu restabelecimento de saúde é restrito ao santo, [...] o Pai colocou o jogo de búzio pra mim e minha santa quer um bori, [...] minha saúde é assim: eu tenho problema de artrose, sou hipertensa, diabética, mas de um tempo pra cá, da minha assiduidade no Candomblé eu melhorei 60\% minha saúde. Eu passei um ano andando de muleta, eu atribui ao meu afastamento do candomblé, quando voltei fiquei boa, não ando mais de muleta (Membro de Terreiro, 2).

Segundo Buchillet (1991), nas comunidades de raízes africanas, chamadas tradicionais, o poder explicativo e terapêutico da doença ou de um infortúnio individual ou coletivo se constitui na busca de sentidos. Suas interpretaçóes remetem ao conjunto das representaçóes que os sujeitos fazem de suas atividades na sociedade e no seu meio natural. A doença é pensada e analisada no contexto 
sociocultural no qual presidem a aparição de uma doença, as representaçóes do mundo natural e das forças que a regem e de suas representaçóes, ou seja, estabelece-se uma relação entre o mundo humano e o mundo natural e sobrenatural. Portanto, toda interpretação da doença é inscrita na totalidade do contexto sociocultural de referência, sendo atribuída à doença a intervenção de agentes de ordem biológica, social e da ordem do mundo (cosmológica).

O indivíduo pode ou náo ser causa direta ou indireta de suas próprias doenças, por um comportamento socialmente desviante ou por não cumprimento das regras culturais. Buscam-se as causas na ordem biológica, social ou cosmológica, sendo que o fato mais importante a respeito de uma doença é a tentativa de identificar e compreender as causas que a ocasionaram. Em seguida se estabelecem os níveis de causalidade de cada doença, investigam-se os episódios que vão subsidiar todo o diagnóstico e tratamento.

Primeiro o sujeito estabelece seu próprio diagnóstico, juntamente com seus familiares, através do que observam das manifestaçôes patológicas e causas da aparição. Então, buscam-se os alívios dos sintomas no qual o tratamento é feito com as plantas, através de lambedores, chás, banhos etc. Segundo, a doença é classificada e procurar-se-á a causa última, relacionando-a com a doença particular do indivíduo no seu meio físico e social. É o caráter crônico que colocará a doença em um nível de interpretação mais profunda, nessa situação o tratamento visará mais a causa cosmológica social da doença.

Aqui a gente cuida não só da saúde orgânica, cuida da saúde emocional. [...] a gente tem que estar bem com nosso Orixá, [...] estar bem consigo mesmo. Aqui a gente tem que separar o que é do Orixá e o que é orgânico, quando o Pai [Babalorixá] diz 'isto não tem nada a ver com o Orixá, vá procurar o médico (Membro do Terreiro, 4).

Assim, vemos que a importância da medicina ocidental não é desconsiderada durante as falas dos membros do terreiro, de modo que eles demonstram reconhecer que é possível o diálogo entre os diferentes saberes, inclusive fazendo "encaminhamentos" para o médico, quando avaliam necessário. Contudo, a precarização do serviço público de saúde também é evidenciada nas falas, demonstrando a insatisfação dos membros do terreiro, quando estes precisam de atendimento médico, em contraposição ao atendimento das demandas de saúde no próprio espaço do terreiro, que, como já colocado, se configura como um ambiente acolhedor e resolutivo.
No SUS é o caos total [...] saúde só está no papel, a promoção não existe. Não há o que comparar. No terreiro existe uma promoção de saúde. Quando um filho não está legal o Pai pergunta o que é que está acontecendo. Ele conhece quando a gente não está legal. [...] quando é pra ser resolvido aqui se resolve (Membro do Terreiro, 4).

Desse modo, vemos que a relação dos membros do terreiro com os saberes científicos, com as políticas afirmativas e com o uso da USF aparenta ser mais tranquila e maior do que o apresentado pelos profissionais de saúde em relação aos saberes populares, às políticas afirmativas e ao espaço do terreiro, como veremos a seguir.

- A percepçáa dos profissionais de saúde sobre os usuários e a Politica Nacional de Saúde Integral da População Negra, com enfoque nos povos de terreiro.

Em relação a esta categoria, ficou visível nas práticas e falas dos profissionais da USF o desconhecimento da Política Nacional de Saúde Integral da População Negra, com enfoque nos povos de terreiro. Os profissionais de saúde demonstram ter conhecimento da existência de vários terreiros no território em que está localizada a Unidade, fazem menção a alguns e as suas práticas, mas sempre de forma superficial, do ouvir dizer, conforme trechos das entrevistas a seguir:

Eu sei que tem um terreiro atrás da Unidade, logo na esquina. [...] sei que na comunidade tem bastante, mas não conheço. Foi uma coisa que fiquei pensando: nesses 10 anos, nunca atendi alguém que tenha dito que fazia parte do candomblé. No meu atendimento eu procuro saber se tem alguma restrição em relação há algum alimento [...]. Na verdade, ao candomblé nunca (Membro da Unidade de Saúde 4).

Não conheço as açôes de saúde do povo de terreiro. Não sei! Já ouvi falar dos banhos de ervas que eles utilizam, mas nunca tive oportunidade de acompanhar de perto. Nunca realizei nenhum atendimento no terreiro. Não fiz algo diferenciado (Membro da Unidade de Saúde, 1).

Não conheço nada da cultura negra. [...] Não tenho conhecimento. O que percebo é que a cultura é grande, mas especifica para o povo de terreiro não vejo. [...] pelos menos aqui a gente não percebe isso não [...]. Eu já ouvi falar que eles têm os chás, os rituais de cura. Eles participam e acreditam em suas práticas e isso a gente sabe que ajuda no reestabelecimento de saúde (Membro da Unidade de Saúde, 5). 
A superficialidade do conhecimento sobre a Política Nacional de Saúde Integral da População Negra por parte dos profissionais se evidencia. Outra questáo é o modo como os processos de trabalho na USF estão organizados é colocado, por um profissional, como elemento que dificulta o estabelecimento do diálogo e, até mesmo, o planejamento ou execuçáo de uma açáo conjunta com os membros do terreiro que realizam açóes curativas.

A gente tem dificuldade de formar grupo, extrapolar o tratamento ambulatorial convencional na Unidade de Saúde. A Unidade de Saúde não dá essa estrutura. Então [o que é feito] é a marcação de consulta. Você atende e vai embora (Membro da Unidade de Saúde, 3).

O depoimento do entrevistado vai de encontro aos argumentos de Barros (2004, p. 91), quando afirma que a política de saúde "tem poder suficiente para promover necessidades novas e estilos de vida coerentes com as normas e valores estruturalmente necessários". No entanto, o problema da relaçáo entre técnico e população usuária do serviço de saúde se efetiva, no plano institucional, em meio às contradiçôes e paradoxos que estão presentes na sociedade e na cultura. Encontramos também falas que contradizem os princípios preconizados pela Política Nacional de Atenção Básica (PNAB), segundo a qual os serviços devem desenvolver uma atenção integral, que impacte na situação de saúde e autonomia das pessoas e nos determinantes e condicionantes de saúde das coletividades, com foco na prevenção e promoção de saúde e valorização das diversidades culturais do território (BRASIL, 2012).

[...] é difícil fazer prevenção e promoção quando o local que você atua é curativo (Membro da Unidade de Saúde, 1).

[...] no contexto da Unidade de saúde os profissionais são muito técnicos, dão muita ênfase à clínica (Membro da Unidade de Saúde, 2).

O despreparo, decorrente da falta de formação inicial e continuada, para lidar com as especificidades de grupos étnico-raciais que compartilham de uma cultura própria, foi uma questão que emergiu de modo significativo nessa categoria temática.

[...] Nunca recebi formação específica [...] Conheço essas práticas porque já fui visitar. Nunca realizei nenhum atendimento no local de terreiro. Já atendi várias pessoas que frequentam terreiro. Por isso, eu tenho essa vivência, porque quando eu encontro, eu questiono para ver o ambiente que ele vive, como está na vida, com o que ele trabalha. Se eu vou saber a vida daquela pessoa, en vou saber qual a direção dele. [...] Nunca ouvi falar de políticas afirmativas do SUS, nem em política de saúde para os povos de terreiros. Nunca soube. Nunca tive seminário, alguma coisa que a saúde dispóe (Membro da Unidade de Saúde, 2).

A gente sabe que saúde não só diz respeito ao corpo, está voltada para um contexto, então, com certeza eles [povo de terreiro] têm sim, mas que a gente não tem conhecimento. Aqui o médico, não todos, em relação à atenção, a queixa trazida pelo usuário, ele não foca nela [...] porque infelizmente o sistema está sobrecarregado [...]. Nunca realizei nenhuma ação num terreiro [...] Não conheço nada de suas politicas dentro do SUS. A gente sabe o básico e não tem uma preparação para lidar com as particularidades do individuo. [...] seria interessante o trabalho diferenciado a esse tipo de população, conhecer mais sua cultura, [...] suas práticas para que a gente fizesse um elo das duas ciências (Membro da Unidade de Saúde, 5).

A partir dos depoimentos acima, é possível afirmar que há certo reconhecimento, por parte dos profissionais, da importância de se considerar os aspectos culturais na abordagem das condições de saúde das pessoas. Contudo, há um desconhecimento sobre as políticas afirmativas e um distanciamento do espaço do terreiro, evidenciado pelo fato de os profissionais da USF nunca terem realizado uma ação no terreiro, mesmo estando no mesmo território. Assim, embora alguns profissionais pareçam dar sinais de um olhar mais sensível ao contexto identitário e cultural do usuário do serviço, talvez ainda não seja possível, nesse caso, falar em diálogo entre essas práticas distintas de cuidado, mas talvez, uma aproximação, um afetamento.

Nesse sentido, pensamos que o reconhecimento e a valorização da diversidade cultural do território são um passo importante na direção de um possível diálogo entre os saberes e práticas em questão. O conhecimento das políticas afirmativas também poderia contribuir com tal diálogo, beneficiando o usuário através de uma atenção que valoriza e leva em consideraçáo seu universo cultural. Dessa forma, vemos que alguns profissionais conseguem avançar e sinalizar possibilidades e a necessidade da dialogicidade, mesmo com os limites institucionais, que podem dificultar a integração e a troca de conhecimentos entre os sujeitos desses dois espaços estudados.

Saúde não existe regras, existe acomodar para resolver [...] Tenho mais de 20 anos de atuação. Conheço vários terreiros, inclusive, eu já visitei [...] Eles usam muitas ervas e banhos, tanto 
ervas cheirosas, como fedorentas, as cheirosas é para proteção e as fedorentas é para limpar o mal. De vez em quando, eles mandam tomar banho de sal grosso do pescoço para baixo, pegar alfazema e colocar na água, se banhar para abrir os caminhos. [...] Aqui tem uma senhora que eu atendo, [...] ela é tida como louca porque ao passar por uma casa, batia e entrava para curar as pessoas. [...] ela tem mediunidade, [...] eu fui fazendo um levantamento, tive necessidade de formular o meu modo de pensar (Membro da Unidade de Saúde, 2).

Verificamos que o delineamento das açóes e os procedimentos usados pelos atores sociais estão inseridos no domínio dos macros processos socioculturais dos quais fazem parte. Desse modo, a escolha de um determinado processo terapêutico se inscreve no mundo sociocultural histórico.

Nunca realizei nenhuma ação no terreiro. Já atendi pessoas que frequenta, eles falam que tem essa prática de fé. Eu trato de entender que alguns pacientes têm esse tipo de fé, de prática. Eles interpretam alguns fenômenos psíquicos de uma forma particular, então é importante saber que essa pessoa tem um estilo de vida e que para ela determinadas sensaçôes ou vivências trazem aquilo como algo normal, espiritual, então eu tento entender o paciente desse seu jeito. [...] o saber da crença do paciente nos ajuda a entender e não criar rótulo [...] isso ajuda saber a fé que o paciente pratica (Membro da Unidade de Saúde, 3).

Apesar do estranhamento e distanciamento por parte de alguns dos profissionais acerca das práticas de cuidado no terreiro, notamos que outros reconhecem a existência de um saber que precisa ser levando em consideração na sua ação profissional, reconhecendo, assim como enfatizam Alves e Souza (1999), que os processos de escolha de tratamento são açôes humanas significativas e estão em estreita relação com o mundo intersubjetivo, nos quais os sujeitos buscam estabelecer significados com suas cosmovisôes.

\subsection{Terapia Ocupacional Social, diversidade cultural e mediação de diálogos}

Segundo Barros (2004), a emergência da questáo social na Terapia Ocupacional se deu através da análise teórica que tem como perspectiva o entendimento de que o adoecimento é resultante de fenômenos individuais, sociais, médicos e existenciais, aos quais são atribuídos diversos significados. Portanto, o adoecimento náo está desconectado da realidade dos sujeitos. Esta perspectiva é resultante de uma visão crítica iniciada na profissão na década de 1970 , e aprofundada nas décadas seguintes, de modo que, a partir dos anos 1990, o debate apontou para a importância da Terapia Ocupacional Social como medidora de conflitos e de negociação cultural e relacional.

Assim, a Terapia Ocupacional Social incorporou para si o estudo de categorias como cultura, conflito social, exclusão e marginalização, cidadania, políticas públicas, dentre outras questóes que são fundamentais à prática do terapeuta ocupacional. Com isso, a área passou a desenvolver recursos teóricos e metodológicos próprios, com base na crítica à institucionalização e medicalização dos problemas sociais, e na constituição de processos de reconhecimento e implementação do caráter universal dos direitos sociais.

Para Barros (2004), o trabalho de transformaçáo da assistência exigiu uma competência interdisciplinar e intersetorial, que provocou respostas inovadoras para novos serviços criados, sendo preciso transcender a clínica e confrontar com o território. Torna-se importante, nesse campo de conhecimento teórico e prático, refletir, articular e produzir conhecimento ao nível do microssocial e do macroestrutural, político-operacional e da atenção às particularidades dos sujeitos. Portanto, para a efetivação dessas proposiçóes o terapeuta ocupacional precisa rever e reformular conceitos no intuito de reorientar o seu fazer profissional.

Para isso, é preciso compreender saúde e doença como produção social, romper com a separação existente entre conhecimento científico e popular, razáo e emoção, objetividade e subjetividade, individual e coletivo, técnica e política, uma vez que essas dicotomias desconsideram a experiência do sensível e do vivido, do real e do imaginário. Percebe-se, então, que os serviços sociais, dentre os quais os de saúde, podem promover mudanças na sua forma de organização e atuação, no sentido de promover novas práticas coerentes com as diferentes realidades socioculturais.

Compreendendo que as formas de construção dos saberes, conhecimentos e de suas transmissóes são distintas entre os saberes tradicionais e os acadêmicos, estes últimos construídos nos espaços de formação dos profissionais de saúde, torna-se fundamental um papel mediador e estimulador da interação entre eles, visando à construção de práticas de respeito ao outro, que valorizem a alteridade e promovam açóes emancipatórias. É, portanto, nesse campo de tensão e conflitos, permeados por preconceitos 
e vulnerabilidades, que a atuação profissional do terapeuta ocupacional é convocada para mediar e fortalecer o diálogo.

O desafio está em criar meios de promoção desse diálogo entre os diversos atores do território, incluindo os profissionais da USF, os membros do terreiro responsáveis pelas práticas de saúde e a comunidade em geral. Pensamos que a criação no território de um espaço que possa se configurar como um centro de convivência e cultura pode se constituir em um importante meio para a articulação comunitária, espaço este a ser utilizado para realização de diversas atividades que contribuam para o reconhecimento da diversidade cultural, resgate e manutenção da memória local, para a difusão dos saberes e fazeres tradicionais e científicos, fortalecendo os laços comunitários e dirimindo possíveis conflitos decorrentes da diversidade de crenças que habitam o mesmo espaço. A exploração de dispositivos já existentes no território como uma associação comunitária, clube ou o próprio terreiro também pode servir de local para tal, na impossibilidade da criação de um novo equipamento.

Junto à USF o terapeuta ocupacional pode estar difundido as políticas afirmativas do Sistema Único de Saúde (SUS) e reforçando o papel-chave do profissional para sua efetivação. Também pode criar estratégias para aproximar os profissionais $\mathrm{da}$ USF do terreiro, no sentido de estabelecer parcerias, uma vez que o cuidado em um destes espaços não anula a existência e práticas de cuidado no outro, quando há respeito mútuo e valorização das diferenças. A realização de oficinas conjuntas, para os membros do terreiro que executam as práticas de cuidado em saúde e profissionais da USF, pode ser uma estratégia eficaz de troca de saberes e de ressignificação de possíveis relaçôes já existentes, marcadas pelo preconceito.

Estes são apenas alguns exemplos de ações que o terapeuta ocupacional pode estar lançando mão para mediar diálogos no contexto em estudo, contudo cabe ao profissional identificar as especificidades e potencialidades da realidade em que está inserido e articular com os seus conhecimentos técnicos, éticos e políticos para estabelecer estratégias de ação.

A partir da realidade estudada, observamos que esse diálogo se apresenta como indispensável para a efetivação das políticas afirmativas do SUS, a exemplo da Política Nacional de Saúde Integral da População Negra, para uma atenção integral aos sujeitos alvos dessas políticas. Contudo, sabemos que o diálogo nem sempre é fácil ou pacífico, uma vez que os saberes em questão partem de valores e visóes de mundo diferentes, muitas vezes, inconciliáveis.
Nesse campo de discussão e atuação, o conceito de rede social é recuperado como parte de uma formulação da ação profissional na Terapia Ocupacional Social e decorre do reconhecimento de que trabalhar junto significa troca de saberes: único caminho para uma ação profissional partilhada, dialogada. Não se trata de retórica, mas de assumir que vivemos em um contexto de cadeias sociais de interdependência (BARROS et al., 2007).

Segundo Barros et al. (2007), valorizar a diversidade com provocação para revisões teóricas e para novas formulaçóes de ação em Terapia Ocupacional significa reconhecer que há um público-alvo, diferenciado entre si de muitas formas, mas que cada pessoa combina e realiza identidades plenas a partir de marcas de identificação comuns de uma coletividade.

Sendo assim, faz sentido afirmar que a Terapia Ocupacional Social estimula o conhecimento e a valorização de realidades culturais específicas, a exemplo dos povos de terreiros, nas quais muitas vezes os sujeitos se encontram em situação de vulnerabilidade, em decorrência de processos de desqualificação social por questôes étnicas e raciais. Assim, atualmente, a Política Nacional de Saúde Integral da População Negra demanda a atuação de profissionais que possam mediar diálogos, fazer negociaçóes culturais e fortalecer esses coletivos e as suas práticas.

Exige-se, nesse campo, a capacidade do profissional para construir intervençóes coerentes com as culturas dos diferentes grupos e comunidades e com as reais necessidades sociais, fato que determina uma ruptura com ações moduladas por procedimentos técnicos pré-estabelecidos e conservadores. Para que isso seja possível, faz-se necessária uma redefinição de atividade, na qual passe a se constituir enquanto instrumento para o desenvolvimento do indivíduo, alimentado pelas dimensóes econômica, sociopolítica, cultural e afetiva (BARROS et al., 1999). A atividade, por ser um processo relacional, torna-se um importante recurso mediador de diálogos, sendo necessário reconhecer que durante o diálogo podem ser gerados conflitos, uma vez que estão em jogo relaçóes de poder, que também precisarão de mediação.

A nossa perspectiva é de que o diálogo entre os saberes acadêmicos e tradicionais é possível e deve se constituir como um princípio que fundamenta a atuação do terapeuta ocupacional junto às comunidades e povos tradicionais, por considerarmos que a relação dos profissionais da saúde com os povos de terreiros pode ou não vir a fortalecer relaçôes hierarquizantes e discriminatórias, a depender da visão de mundo do profissional. 


\section{Considerações finais}

A pesquisa revelou um diálogo muito frágil entre os saberes científicos e tradicionais, principalmente na Unidade de Saúde. Não há entendimento nem conhecimento da existência de uma política de saúde específica, garantida pela Portaria no 971/MS, que trata das práticas integrativas e complementares do SUS e que atenda às orientaçóes OMS quanto à valorização das medicinas tradicionais, visando à desestigmatizaçáo e valorização dos saberes e práticas terapêuticas de matriz africana como fundamentais.

Esta realidade abre um importante espaço de atuação para o terapeuta ocupacional, enquanto profissional que pode agir visando à promoção do diálogo entre esses diferentes atores de um mesmo território. A mediação de diálogos e negociações culturais constitui um princípio fundamental na atuação do terapeuta ocupacional no campo social, sendo a cultura e a atividade criadoras de possibilidades de interaçôes sociais entre diferentes grupos sociais. É necessária a clareza de que o diálogo só será possível pela dialética, pelo acolhimento, pela capacidade de movimentar-se dentro de um campo plural, diverso, dado pelas diferentes histórias de vida.

Nesse contexto, este artigo tem a intenção de refletir e construir novos conhecimentos que fundamentem a prática do terapeuta ocupacional junto aos povos de terreiros. Consideramos importante conferir significados às açôes e atividades desses povos, sendo fundamental aproximar os saberes construídos academicamente e os tradicionais e estabelecer relaçóes entre eles a partir dos elementos culturais, sendo a mediação de diálogos essencial à efetivação das políticas afirmativas, açôes estas que podem fazer parte do universo de atuação do terapeuta ocupacional.

\section{Referências}

ALVES, P. C.; SOUZA, I. M. Escolha e avaliação de tratamento para problemas de saúde: consideraçôes sobre o itinerário terapêutico. In: RABELO, M. C.; ALVES, P. C.; SOUZA, I. M. (Org.). Experiência de doença e narrativa. Rio de Janeiro: Fiocruz, 1999. p. 125-138.

ARAÚJO, A. M. Cultura popular brasileira. São Paulo: Melhoramento, 1973.

BARBOSA, J. G. O diário de pesquisa: o estudante universitário e seu processo formativo. Brasília: Liberlivro, 2010.

BARDIN, L. Análise de conteúdo. Lisboa: Ed 70, 2011.

BARROS, D. D. Terapia Ocupacional social: o caminho se faz do caminhar. Revista de Terapia Ocupacional da Universidade de São Paulo, São Paulo, v. 15, n. 3, p. 90-97, 2004.

BARROS, D. D.; ALMEIDA, M. C.; VECCHIA, T. C. Terapia Ocupacional social: diversidade, cultura e saber técnico. Revista de Terapia Ocupacional da Universidade de São Paulo, São Paulo, v. 18, n. 3, p. 128-134, 2007.

BARROS, D. D.; GHIRARDI, M. I. G.; LOPES, R. E. Terapia Ocupacional e Sociedade. Revista de Terapia Ocupacional da Universidade de São Paulo, São Paulo, v. 10, n. 2, p. 69-74, 1999.

BASTIDE, R. Estudos Afro-Brasileiros. São Paulo: Perspectiva, 1983.

BRASIL. Decreto no 6.040, de 7 de fevereiro de 2007. Institui a política nacional de desenvolvimento sustentável dos povos e comunidades tradicionais. Diário Ofcial [da] República Federativa do Brasil, Brasília, DF, 8 fev. 2007. Disponível em: <http://www.planalto.gov.br/ ccivil_03/_ato2007-2010/2007/decreto/d6040.htm>. Acesso em: 14 fev. 2014.

BRASIL. Ministério da Saúde. Portaria no 992, de 13 de maio de 2009. Institui a política nacional de saúde integral da populaçáo negra. Diário Oficial [da] República Federativa do Brasil, Brasília, DF, 14 maio 2009. Disponível em: <bvsms.saude.gov.br/bvs/saudelegis/gml2009/ prt0992_13_05_2009.html>. Acesso em: 3 out. 2013.

BRASIL. Ministério da Saúde. Secretaria de Atenção à Saúde. Departamento de Atenção Básica. Política nacional de atenção básica. Brasília: MS, 2012.

BUCHILLET, D. A. Antropologia da doença e os sistemas oficiais de cura. In: BUCHILLET, D. (Org.). Medicinas tradicionais e medicina ocidental na Amazônia. Belo Horizonte: MPEG/ CNPQ/ SCT/ PR/ CEJUP/ UEP, 1991. p. 21-44.

CAMARGO, M. T. L. A. Medicina popular. Rio de Janeiro: Campanha de Defesa do Folclore Brasileiro, 1976.

CANGILHEM, G. O Normal e o patológico. Rio de Janeiro: Forense Universitária, 1978.

CZERESNIA, D. O conceito de saúde e a diferença entre prevenção e promoção. Caderno de Saúde Pública, Rio de Janeiro, v. 15, n. 4, p. 701-710, 1999.

GEERTZ, C. A interpretação das culturas. Rio de Janeiro: LTC, 1989.

HALL, S. A identidade cultural na pós-modernidade. Rio de Janeiro: DP\&A, 1999.

MINAYO, M. C. S. O desafio da pesquisa social. In: DESLANDES, S. F. (Org.). Pesquisa social: teoria, método e criatividade. Petrópolis: Vozes, 2012. p. 9-15.

MINAYO, M. C. S. O desafio do conhecimento: pesquisa qualitativa em saúde. São Paulo: HUCITEC/ABRASCO, 2010. 
MORIN, E. O Problema epistemológico da complexidade. Portugal: Publicações Europa-América, 2002.

MOTTA, R. A cura no xangô de Pernambuco: o rito do amassi como terapia. In: PARRY, S. (Org). Sistema de cura: as alternativas do povo. Recife: Universidade Federal de Pernambuco, 1988. p. 78-88.

OLIVEIRA, F. Saúde da população negra. Brasília: Organização Pan-Americana da Saúde, 2003.
ORGANIZAÇÃO DAS NAÇÓES UNIDAS - ONU. Relatório da conferência mundial contra o racismo, discriminaçâo racial, xenofobia e formas correlatas de intolerância. Durban: ONU, 2001. Disponível em: <www.gddc. pt/direitos-humanos/Racismo.pdf $>$. Acesso em: 20 set. 2013.

SANTOS, J. E. Os nagô e a morte: padeásésé e o culto êgun na Bahia. Rio de Janeiro: Vozes, 1993.

\section{Contribuição dos Autores}

Todos os autores participaram da concepção, redação do artigo e aprovaram a versão final do texto.

\section{Notas}

${ }^{1}$ A Política Nacional de Desenvolvimento Sustentável para Povos e Comunidades Tradicionais, instituída pelo Decreto 6040, de 2007, em seu artigo 30, inciso I, estabelece como "Povos e Comunidades Tradicionais: grupos culturalmente diferenciados e que se reconhecem como tais, que possuem formas próprias de organização social, que ocupam e usam territórios e recursos naturais como condição para sua reprodução cultural, social, religiosa, ancestral e econômica, utilizando conhecimentos, inovaçóes e práticas gerados e transmitidos pela tradição” (BRASIL, 2007, p. 01).

${ }^{2}$ Em complementariedade com a Política Nacional de Desenvolvimento Sustentável dos Povos e Comunidades Tradicionais, cujos objetivos específicos contemplam garantir aos povos e comunidades tradicionais o acesso aos serviços de saúde de qualidade e adequados às suas características socioculturais, suas necessidades e demandas, com ênfase nas concepçôes e práticas da medicina tradicional, assim como, criar e implementar, urgentemente, uma política pública de saúde voltada aos povos e comunidades tradicionais, dentre outros.

${ }^{3}$ A Política Nacional de Desenvolvimento Sustentável dos Povos e Comunidades Tradicionais tem como objetivo geral o reconhecimento, a valorização e o respeito à diversidade socioambiental e cultural dos povos e comunidades tradicionais, levando-se em conta, dentre outros aspectos, os recortes etnia, raça, gênero, idade, religiosidade, ancestralidade, orientação sexual e atividades laborais, entre outros, bem como a relaçáo desses em cada comunidade ou povo, de modo a não desrespeitar, subsumir ou negligenciar as diferenças dos mesmos grupos, comunidades ou povos ou, ainda, instaurar ou reforçar qualquer relação de desigualdade.

${ }^{4}$ As Casas Tradicionais de Matriz Africana são hoje consideradas como espaços promotores de saúde, por seus conhecimentos fitoterápicos e práticas de acolhimento e cuidados para com as pessoas que ali acorrem, pelo Ministério da Saúde, que vem apoiando diversas açôes de qualificação e potencialização das suas tradiçôes. Também o Conselho Nacional de Segurança Alimentar (CONSEA) reconhece o papel exercido ao longo da história e, atualmente, pelas Comunidades Tradicionais de Matriz Africana, para a segurança alimentar e nutricional de um grande número de pessoas negras e periféricas, em situaçấo de extrema pobreza, por ser o alimento um princípio fundamental das práticas socioculturais inerentes a estas tradiçôes.

${ }^{5} \mathrm{O}$ jogo de búzios, com o qual os sacerdotes ou sacerdotisas realizam seus diagnósticos e consultam sobre a conduta a ser seguida no cuidado necessário com o filho ou filha de santo, ou mesmo um consulente.

${ }^{6}$ Babalorixá é o nome dado ao Sacerdote do Orixá do Culto de Ifá, das culturas Jejè e Nagô.

${ }^{7}$ O projeto foi aprovado pelo Comitê de Ética em Pesquisa com Seres Humanos da Universidade Estadual de Ciências da Saúde de Alagoas. 